\title{
Yield response of Nigerian rice agriculture (1970-2017)
}

\author{
Ajiboye A. ${ }^{*}$, Aturamu O. A. ${ }^{2}$, Amao S.A. ${ }^{3}$ and Farayola C. $0 .{ }^{4}$ \\ ${ }^{1}$ Department of Agricultural Economics and Extension Services, Ekiti State University P. M. B. 5363, \\ Ado Ekiti, Ekiti State, Nigeria. \\ ${ }^{2}$ Department of Agircultural science, Bamidele Olumilua University of Education Science and Technology, \\ Ikere Ekiti, Nigeria. \\ ${ }^{3}$ Department of Agricultural Technology, Oyo State College of Agriculture Technology, Oyo State, Nigeria. \\ ${ }^{4}$ Agricultural Development Management Department, General Management Division, Kwara State, Nigeria. \\ *Corresponding author. Email: abiodun.ajiboye@eksu.edu.ng
}

Copyright @ 2021 Ajiboye et al. This article remains permanently open access under the terms of the Creative Commons Attribution License 4.0, which permits unrestricted use, distribution, and reproduction in any medium, provided the original work is properly cited.

Received 30th April, 2021; Accepted 16th June, 2021

\begin{abstract}
Over the years, the domestic supply of rice has wielded great influence on the food security and selfsufficiency status of Nigerian households, making it one of the principal staple crops in the country. Against this backdrop, this study examines the yield response of rice to climate and non-climate variables in Nigeria. The study was conducted from data extracted from the Food and Agriculture Organization (FAO) database from 1970 to 2017. The data was augmented with rainfall data from National Meteorological Center (NIMET). The Johansen Error Correction Model in a cointegration framework was employed to test the responsiveness of supply to the factors considered. The study revealed that rice yield in Nigeria is non-responsive to real price, exchange rate and climate variables. However, fertilizer consumption significantly influences rice yield in Nigeria.
\end{abstract}

Keywords: Cointegration, error correction, unit root, yield response.

\section{INTRODUCTION}

The current population of Africa is $1,370,137,088$ based on the latest United Nations estimates (Worldometer, 2021). The Nigerian local economy is still very much agrarian in nature. In 2019, agriculture contributed around 21.91 percent to Nigeria's GDP, 27.38 percent came from industry, and 49.73 percent from the services sector. The sector accounts for $36 \%$ of the nation's labour force. While the external sector is continuously dominated by petroleum, which generates about $95 \%$ of Nigeria's foreign exchange earnings, agriculture contributes less than $5 \%$ (Aaron, 2021; Taiwo, 2020; World Bank, 2004). This overdependence on oil has been a continuous bane on the development of agricultural sector. It is not an overstatement to say that the local Nigeria rice industry, just like many other food crop subsectors (apart from cassava in which Nigeria is already self-sufficient) has failed abysmally in bridging the food supply-demand gap, even since independence. The rate of growth of the Nigerian rice subsector has not been able to adjust or catch up with the rapid urbanization and increase in per capita incomes which stimulate increased rice consumption. This deficit in national rice supply did not just start in recent years. It has attracted attention of several successive Nigerian governments leading to various interventions in the rice subsector of the economy. The Sahelian drought of the early 70 s first prompted the Federal government to establish the River Basin Development Authority in various agro-ecological zones of the country. This was done to boost production and ever since then several food policy and programs were formulated, but have not resulted in self-sufficiency in the rice subsector.

The rice subsector has been constrained by many hurdles such as inconsistent government policies, improper production methods, high cost and scarcity of vital inputs of production, and post-harvest handling and marketing challenges (Boansi, 2014). Osagie (2014) observed that Nigeria currently spends several billions of Naira annually importing rice, a development which, according to the former minister of agriculture is helping to 


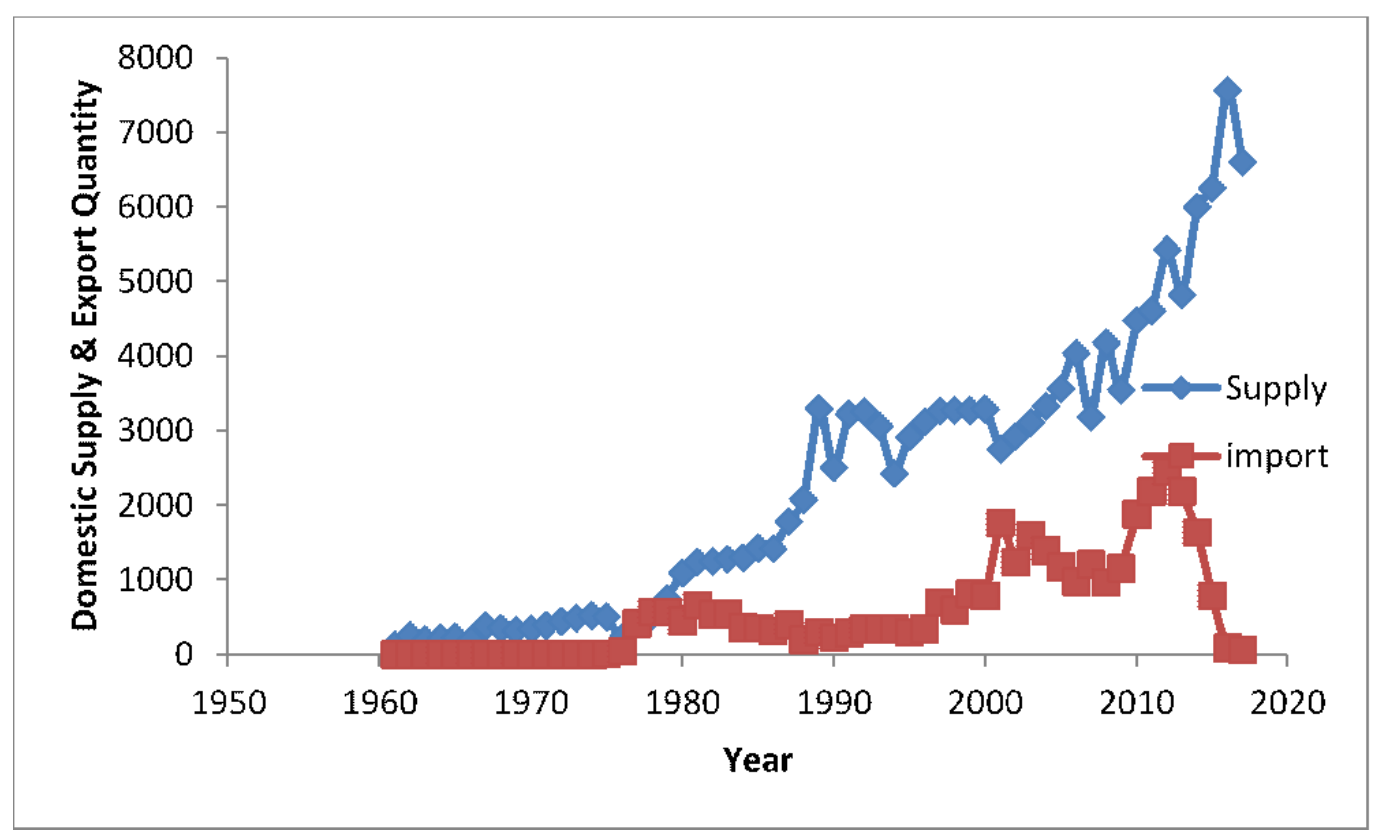

Figure 1. Rice domestic supply and export quantity ('000 tonnes).

put farmers to work in countries like USA, India, and Thailand; (countries where Nigeria mostly imports rice); while putting farmers out of work in Nigeria. The Nigerian government, therefore, came up with a policy decision to ban rice importation completely by 2015. But the unpreparedness of the Nigerian government towards ensuring that these policy intentions were actualized at that time was very clear, because importation continued unhindered. The present government came on board and aggravated the scenario while Nigeria is currently looking inward than ever for her rice consumption. Several incentives were rolled out to local farmers to be able to produce on a larger scale, but illegal smuggling of rice is still an everyday activity in the Nigerian borders just because capacity is lower than challenge.

These efforts are not yielding the desired fruits because of many problems relating to yield, as a component of output against harvested area. The principal challenge is not with harvested area per say as there is no agroecological zones in Nigeria where rice is not cultivated and though Nigeria is currently the largest rice producing country in Africa, the area cultivated to rice still appears small. Available statistics stipulates that, annual rice production in Nigeria increased from 5.5 million tons in 2015 to 5.8 million tons in 2017. The statistic of rice production in Nigeria shows an annual increase of about $5 \%$. For the first half of year 2016 for example, it has already risen by $2.67 \%$. The import rates have also increased to 5,850 from 4,800 during the same period of time (Udemezue, 2018). The demand is so high today, that Nigeria can supply only about half of the domestic demand. Hence external succor, through export is expedient (Figure 1).
According to Ajetomobi (2010), supply response seeks to explain the behaviour change of producers with respect to the production, consumption and exchange decisions for a certain product or a set of products arising from changes in economic incentives. Supply response of crops, as one of the main topics in agricultural development economics, cannot be overemphasized (Mushtaq and Dawson, 2002). This is because the agricultural sector's contribution to the economy is a function of the responsiveness of farmers to economic incentive. Agricultural policies must be put in place to instigate increasing farm production (Rahji and Adewunmi, 2008). Supply response is fundamental to an understanding of this price mechanism (Nerlove and Bachman, 1960; Tanko and Alidu, 2016). Different approaches have been traversed in the empirical works on supply responses of agricultural export commodities in Nigeria and beyond. There are studies that have used various models to explain the causality or the dynamic adjustment between the behavior of some exogenous and endogenous variables, and the agricultural export growth in an economy or in a group of countries. Amongst that focused on the short run and long run supply response of a particular crop to changes in output and input prices in Nigeria are Lukonga (1994), Kwanashie et al. (1998), Antai (2006), Mesike et al. (2010) and Oni (1969). This study employed the Johansen cointegration procedure to estimate the supply response of rice production to climate variables between 1970 and 2017 in Nigeria. Specifically, the study endeavor to: examine the trend in rice production in Nigeria from 1970 to 2017, examine the effect of climate change on supply response of rice and estimate the short run and long run price elasticity of rice produced in Nigeria 
within the time frame. The hypotheses of this study are stated in the null form as follows: there is no cointegration at all i.e. there is no long run relationship among the variables. While the second hypothesis is that there is at least one cointegration. Meaning that there is at least one long-run relationship among the variables.

\section{MATERIALS AND METHODS}

This study was carried out in six geo-political zones in Nigeria where three States were purposively selected because of their prominent rice production. Secondary data was used for this research. The sources of the data are from the FAOSTAT database of the Food and Agricultural Organization of the United Nations and The Nigerian Meteorological Station (NIMET). The selected data covers a range of 30 years (1970-2017).

\section{Test of stationarity}

The development in the time series modelling points to the need to exercise some caution, by first examining the statistical properties of the series and incorporating these in the final model specification where necessary, in order to guarantee reliable estimates from our regression (Granger and Newbold, 1974). The first step in the analysis was to identify the order of integration of the variables. In this study, the Augmented Dickey Fuller test was estimated to check for the presence of unit root in the variable in case variables do not follow AR (1) process. Stationarity means a stochastic process whose unconditional joint probability distribution does not change when shifted in time and parameter such as variance and mean, which means that it is stable. But when there is no stationarity, it is either increasing or decreasing in which case, there is a trend (this means the mean and variance are not constant). If we run the regression of the nonstationary model, the result will be spurious. It is either there is a very highly significant variable or very high $\mathrm{R}^{2}$. The next thing to do is to get it to be stationary. To do this, is to get the first difference by lagging the variable by one year and subtract it from the original. The practicality behind lagging is that farmers are very much concerned about previous year's production which determines the present. After getting it to be stationary, we now run the regression of the first difference. Economically, it is wrong to base the conclusion on the regression result, because the first difference is different from the original and therefore many things were lost. For example, the elasticity was calculated for the first difference and not for the original model. The process of the unit root test is described in the following models.

We know that $y_{t}=\varphi y_{t-1}+\varepsilon_{t}$. To test whether $\phi$ is equal to 1 , subtracting $y_{t-1}$ from both sides, the AR (1) model can re-written. In the above, a test of $\varphi=1$ is a simple test of whether the parameter on the lagged level of $y$ is equal to zero. This is referred to as the Dickey-Fuller test.

It is also know that the $\mathrm{AR}(3)$ equation $y_{t}-\varphi y_{t-1}-$ $\varphi_{2} y_{t-2}-\varphi_{3} y_{t-3}=\varepsilon_{t}$

Can be written in the backshift operator as:

$\left(1-\varphi_{1} B-\varphi_{2} B^{2}-\varphi_{3} B^{3}\right) y_{t}=\varepsilon_{t}$

The existence of a unit root $B=1$ therefore means that $B=1$ is a solution of the AR polynomial equation:

$1-\varphi_{1} B-\varphi_{2} B^{2}-\varphi_{3} B^{3}=0$

Thus, if we plug $B=1$ we have

$\rho=\varphi_{1}+\varphi_{2}+\varphi_{3}=1$

If there are higher-order AR dynamics (or ARMA dynamics that can be approximated by longer AR terms).

Suppose an $\operatorname{AR}(3) y_{t}-\varphi_{1} y_{t-1}-\varphi_{2} y_{t-2}-\varphi_{3} y_{t-3}=\varepsilon_{t}$

This can be written as a function of just $y_{t-1}$ and a series of differenced lag terms:

$y_{t}=\left(\varphi_{1}+\varphi_{2}+\varphi_{3}\right) y_{t-1}-\left(\varphi_{2}+\varphi_{3}\right)\left(y_{t-1}-y_{t-2}\right)-\varphi_{3}\left(y_{t-2}-y_{t-3}\right)+\varepsilon_{t}$

$y_{t}=\rho_{1} y_{t-1}+\rho_{2} \Delta y_{t-2}+\rho_{3} \Delta y_{t-2}+\varepsilon_{t}$

Having unit root therefore means $\rho_{1}=1$ in $y_{t}=\rho_{1} y_{t-1}+$ $\rho_{2} \Delta y_{t-2}+\rho_{3} \Delta y_{t-2}+\varepsilon_{t}$

Or equivalently $1-\rho_{1}=0$ in $\Delta y_{t}=\left(\rho_{1}-1\right) y_{t-1}+$ $\sum_{j=2}^{\rho} \rho_{j}\left(\Delta y_{t-j+1}\right)+\varepsilon_{t}$

This is called the augmented Dickey-Fuller (ADF) test and this is implemented by $R$ in this analysis

\section{Cointegration analysis and the empirical model specification}

In supply response analysis, many authors have performed cointegration test using different methods such as, the residual-based approach of Phillips and Ouliaris (1998), the Engle-Granger two-step estimation technique of Engle and Granger (1987) or the Johansen Full Information Maximum Likelihood test of Johansen and Juselius (1990). In this study, Johansen Full Information Maximum Likelihood test was adopted. This approach was chosen because the method allows for all possible cointegrating relationships and permits empirical determination of the number of cointegrating vectors (Kuwornu et al. 2011). The other two methods, however, assume a single cointegrating vector. Besides, in estimating short-run coefficients, guiding by and consistency with 
long-run relationships are maintained when the Johansen method is used.

The Johansen approach commences with the definition of a Vector Autogression given by

$X_{t}=\Pi 1 X_{t}+\Pi 2 X_{t-2}+\ldots+\Pi_{p} X_{t-p}+\mu_{t}$

Where $X t$ is an $(n \times 1)$ vector of $I(1)$ variables, $\Pi 1$ through $\Pi p$ represent $(m \times m)$ matrix of coefficients, and $\mu t$ is $(n \times 1)$ vector of error terms. If we assume that $\mathrm{Xt}$ is nonstationary, equation (1) can be re-written in an error correction form as;

$\Delta X_{t}=\Gamma 1 \Delta X_{t-1}+\Gamma 2 \Delta X_{t-2}+\ldots . \Gamma p-1 \Delta X_{t-p}+1-$ $\Pi \Delta X_{t-p}+\mu_{t}$

Where:

$\Gamma 1=\Pi 1-I, \Gamma 2=\Pi 2-\Gamma 1, \Gamma 3=\Pi 3-\Gamma 2$

And

$\Pi=I-\Pi 1-\Pi 2-\ldots-\Pi p \Gamma i$

This gives the short-run estimates while $\Pi$ gives the longrun estimates. The matrix $\Pi$ determines the extent to which a given system is cointegrated and is called the impact matrix. This implies that information on the number of cointegrating relationships among the variables in $\mathrm{Xt}$ is given by the rank of the matrix $\Pi$. If the rank of $\Pi$ matrix $r$, is $0<r>n$, there are $r$ linear combinations of the variables in Xt that are stationary (Kuwornu et al., 2011). Thus, $\Pi$ can be decomposed into two matrices $\alpha$ and $\beta$, where $\alpha$ represents the error correction term and measures the speed of adjustment in $\Delta \mathrm{Xt}$ and $\beta$ contain $r$ co-integrating vectors. Should there be variables which are I(0) and are significant in the long-run co-integrating space but affect the short-run model, equation (2) is re-written as follows:

$\Delta \mathrm{xt}=\Gamma 1 \Delta \mathrm{xt}-1+\Gamma 2 \Delta \mathrm{xt}-2+\ldots+\Gamma \mathrm{p}-1 \Delta \mathrm{xt}-\mathrm{p}+1-\Pi \mathrm{xt}-\mathrm{p}+\mathrm{vDt}+\mu_{t}$

Where Dt represents the $\mathrm{I}(0)$ variables. In identifying the number of cointegrating vectors, two likelihood ratios (LR) tests are used. These are the trace test and the maximum eigenvalue tests (Johansen, 1988; Johansen and Juselius, 1990). The trace test is a joint test of the null hypothesis of $r$ cointegrating vectors against the alternative that it is greater than $r$. The trace test statistic is given as:

$\operatorname{Jtrace}(r)=-T \sum p_{i}=r+1 \ln \left(1-\lambda_{i}\right)$

This is the choice in this study. The maximum eigen value test on the other hand conducts separate tests on the individual eigen values for a null hypothesis that the number of cointegrating vectors is $r$, against an alternative of $r+1$. The test statistic for the maximum eigenvalue test is given as:
$\operatorname{Jmax}(r, r+1)=-T \ln (1-\lambda r+1)$

The trace test according to Harris (1995) shows more robustness to both skewness and excess kurtosis in the innovations than the maximum eigenvalue test. It is therefore selected over the maximum eigenvalue test in the present study. Suggestion was made by Kuwornu et al. (2011) that in using the Johansen Full Information Maximum Likelihood test, the endogenous variables included in the Vector Autoregression (VAR) are all I(1), also the additional exogenous variables which explain the short-run effect are I(0). The model is specified as follows:

$Y t=F\left(R P, R F, F T, E R\right.$ and $\left.\mu_{t}\right)$.

This is explicitly written as:

$Y_{t}=\beta_{0}+\beta_{1} R P+\beta_{2} R F+\beta_{3} F T+\beta_{4} E R+\mu_{t}$

Where: $\mathrm{Y}_{\mathrm{t}}=$ Rice Yield in tonnes, $\mathrm{RP}=$ Real price of rice in Naira, $R F=$ Rainfall in millimetres to represent weather variable, $\mathrm{FT}=$ Fertilizer in tonnes, $\mathrm{ER}=$ the exchange rate of Naira to dollars, ECT = is the error correction term and $\mu_{\mathrm{t}}=$ the stochastic error term

In order to estimate the parameters in $\beta$ in the linear regression, the usual approach is to apply OLS estimation. One way to motivate OLS is to consider the moment condition $E\left[x_{t} \varepsilon_{t}\right]=0$ stating that the explanatory variables should be uncorrelated with the error term (Wooldridge, 2003). In order to apply OLS as a regression model for time series data, there is need to impose assumptions to ensure that a law of large numbers (LLN) applies to the sample averages. There are several ways to formulate the requirements (Davidson, 2001), but in most cases, the assumption of stationarity and weak dependence were made. The idea of a regression analysis for time series data is to use observations from the past to characterize historical relationships. If the historical relationships to explain current and future developments were used, it has to require that the future behaves like the past; and that is exactly the assumption of stationarity. A minimal requirement for an estimator is that it is consistent, so that the estimator converges to the true value as more and more observations were obtained.

\section{RESULTS AND DISCUSSION}

The graphs presented in Figure 2 display the rice production and hectarage trend from 1970 to 2017. From the graph, rice production increased steadily from 1970, though with variations within the years. Towards the end of 2010 , however, there was a sharp decline in production which later picked up and rose steadily towards 2015. A sharp decline was experienced after 2015 and this reached the peak at a point when production nose-dived again. All these rises and falls in production of rice could 


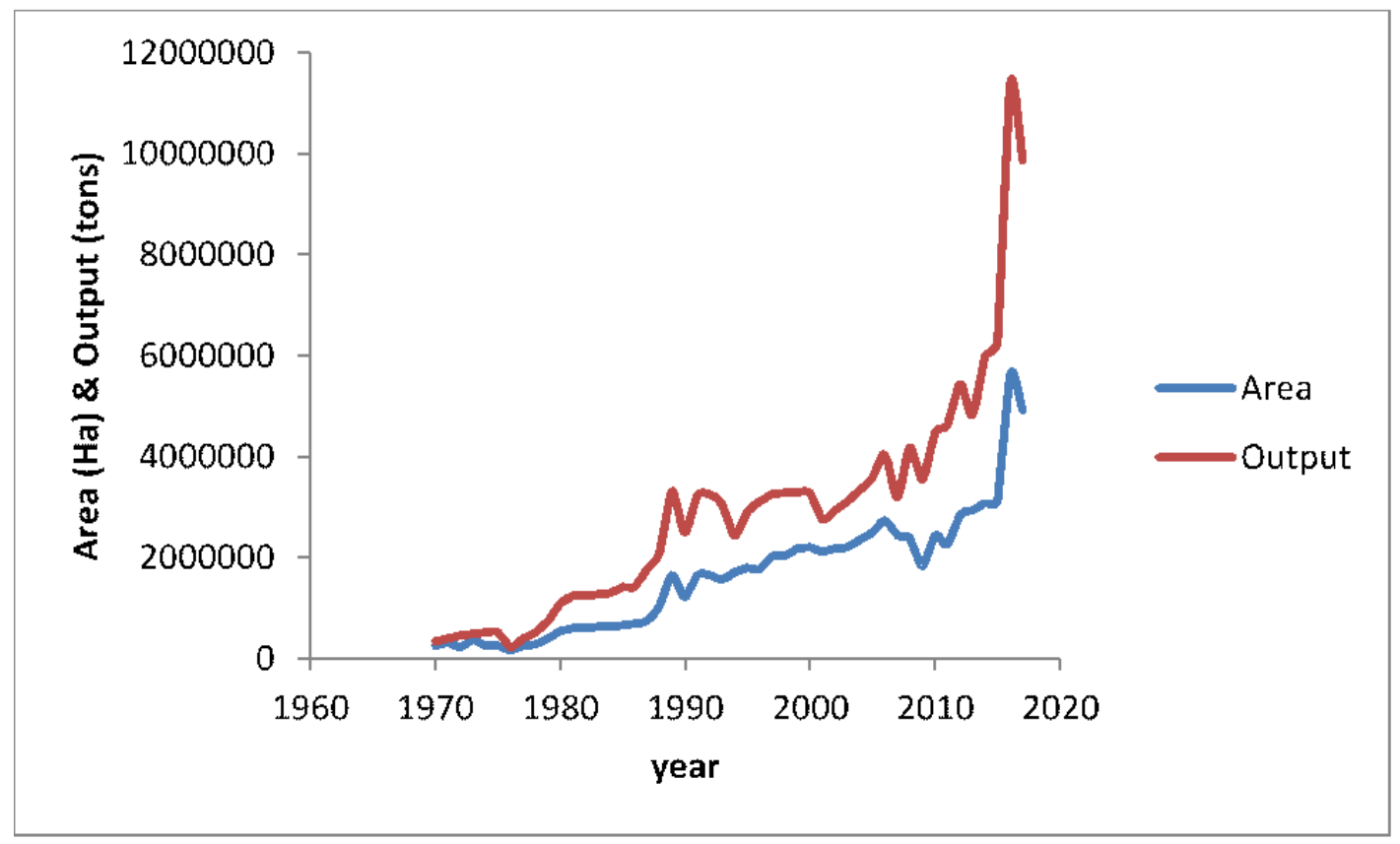

Figure 2. Rice production and hectarage trend (1970-2017).

be as result of weather vagaries and policy somersaults by various governments. The menace of the insurgents in the north east and the nefarious activities of herdsmen were also responsible. The sahelian drought of the 1970s accounted for the conspicuous decline in rice production in those years. Production started increasing by 1976 and trend moved upward till 2017, though there were up and down movements within the year frame. Trend in cultivated area was also similar to what was obtained in the output but with an abrupt decline towards the end of 2017.

\section{Augmented Dikey Fuller Unit Root Test}

The result of the Augmented Dikey Fuller Unit Root Test (ADF URT) is presented in Table 1. According to Table 1, this result is at levels and first difference. Normally, the tstatistics should be less than the critical value meaning that the order of integration is zero and there is stationarity at the levels. The $t$-values for all the variables, except exchange rate were greater than critical values. This established that there was stationarity in all the variables except for exchange rate. Therefore, the order of integration for these is one after first difference.

The next stage of the analysis was the Johansen procedures. This is necessary for the linear combination of the economic series in the output supply response model for rice. The output of the Johansen co-integration test is shown in Table 2. The trace statistic with linear trend in this co-integration test between yield of rice and its correlates was used. The result of the trace is given in Table 2.
When test statistics is $>$ than critical, the hypothesis was rejected. If the hypothesis is rejected, it means there is at least one $L-R$ relationship. The null hypothesis was $\mathrm{We}$ initially rejected because the test statistics was greater than the critical values at all the levels of significance (which looks as if there is more than one) (Table 2). When the integrating rank is 0 , the value of test statistics is very large and greater than critical; hence, the null hypothesis was rejected. This procedure is likewise the same when $r=1$. By the time $r=2$, however, the test statistics is less the critical value, therefore, the null hypothesis was accepted, which means that there is not more than one co-integrating equation.

At $r=1$, it looked as if there is more than one cointegrating equation but at $r=2$, it was discovered that there was not more than 1 . Now that is certain that there is only one co-integrating equation, there is no need to investigate what happens at the larger ranking order.

Table 3 is the result of the short- run analysis for the yield response. The error correction model, Ect 1 is both significant and acceptable at 5 percent because its value is negative and lays between 0 and 1 in absolute terms. Likewise, its $p$-value $(0.0007)$ is less than 0.05 , and then the error correction model variable statistically indicates that the model has 65 percent speed of adjustment. The probability value of $F$ statistics $(0.002)$ is less than 0.05 , therefore the overall systemic model is statistically significant at 5 percent level and there exist a linear relationship between the independent variables and the dependent variable. From the result, Rice yield is nonresponsive to real price, exchange rate and climate variables. However, fertilizer consumption significantly 
Table 1. Augmented Dikey Fuller Unit Root Test (ADF URT).

\begin{tabular}{lccccc}
\hline \multirow{2}{*}{ Variables } & \multicolumn{2}{c}{ At level } & \multicolumn{3}{c}{ First difference } \\
\cline { 2 - 6 } & $\mathbf{t}$ value & $\mathbf{d f}$ & $\mathbf{t}$ value & $\mathbf{d f}$ & Order of integration \\
\hline Real price & -1.466 & 1 & -4.234 & 1 & $1 \mathrm{~d}(1)$ \\
Yield & -2.474 & 1 & -8.044 & 1 & $1(1)$ \\
Rainfall & -3.367 & 1 & -6.036 & 1 & $1(1)$ \\
fertilizer & -0.627 & 1 & -7.401 & 1 & $1(1)$ \\
Exchange rate & -0.526 & 1 & -2.881 & 1 & NS \\
\hline
\end{tabular}

Table 2. Co-integration table.

\begin{tabular}{lccl}
\hline Rank & Trace test & Critical value & Decision \\
\hline 0 & Nan & 78.87 & Reject \\
1 & 65.31 & 55.43 & Reject \\
2 & 27.15 & 37.22 & Accept \\
3 & 12.70 & 23.52 & \\
4 & 2.37 & 11.65 & \\
\hline
\end{tabular}

Table 3. Short run model for rice supply in Nigeria.

\begin{tabular}{lcccc}
\hline Variables & Coefficient & Std. error & t-stat & Prob. \\
\hline Ect 1 & -0.65 & 0.18 & -3.68 & 0.0007 \\
Const & 1.44 & 0.38 & 3.75 & 0.0006 \\
Yt d1 & -0.79 & 0.15 & -5.15 & 0.0000 \\
RP d1 & 0.000012 & 0.000078 & 0.15 & 0.8788 \\
RF d1 & $-1.1 \times 10^{-4}$ & $2.93 \times 10^{-4}$ & -0.38 & 0.71 \\
FT d1 & $7.38 \times 10^{-9}$ & $4.4 \times 10^{-9}$ & 1.67 & 0.10 \\
ER d1 & $-5.60 \times 10^{-4}$ & 0.003 & -0.20 & 0.84 \\
R-squared & 0.32 & & & \\
Adjusted R-squared & 0.42 & & & \\
F-Stat & 4.08 & & & \\
Residual std error & 0.21 & & & \\
p-(F= Stat) & 0.002 & & & \\
\hline
\end{tabular}

influences rice yield in Nigeria. The result is similar to Ayanwale et al. (2011) who found that only fertilizer consumption and area cultivated were responsive to rice supply response in Nigeria.

\section{Conclusion}

The study estimates the elasticity of price and climate variables as affecting the yield of rice in Nigeria. It was discovered that there was instability in rice production and area trends over the years. The Johansen test revealed a fairly high rate of adjustments of the variables to equilibrium, with fertilizer being the driver of this adjustment. It is recommended that policies that support unhindered supply of fertilizers to the rice farmers should be sustained. Other complementary and farmer-friendly policies should also be put in place so as to foster rice yield increase in the nation.

\section{CONFLICT OF INTEREST}

The authors declare that they have no conflict of interest.

\section{REFERENCES}

Aaron O.N. (2021). Distribution of gross domestic product (GDP) across economic sectors Nigeria 2019. Statistica. Retrieved from https://www.statista.com/statistics/382311/nigeria-gdpdistribution-across-economic-sectors/.

Ajetomobi, J. O. (2010): Supply response, risk and institutional change in Nigerian agriculture. African Economic Research Consortium Research Paper 197, Nairobi. 
Antai, A. S. (2006). An empirical investigation of the determinants of non-oil exports in Nigeria 1970 - 2004. Unpublished Ph.D thesis, Department of Economics, University of Calabar, Nigeria.

Boansi, D. (2014). Yield response of rice in Nigeria: A cointegration analysis. American Journal of Agriculture and Forestry, 2(2), 15-24.

Davidson, J. (2001): Econometric theory (reprinted 2001). Blackwell Publishers.

Engle, R. F., \& Granger, C. W. (1987). Co-integration and error correction: representation, estimation, and testing. Econometrica: journal of the Econometric Society, 55(2), 251-276.

Granger, C., \& Newbold, P. (1974). Spurious regression in economics. Journal of Econometrics, 2(2), 111-120.

Harris, R. (1995). Using co-integration analysis in econometric modelling. Oxford University Press, London.

Johansen, S. (1988). Statistical analysis of cointegration vectors. Journal of Economic Dynamics and Control, 12(2-3), 231-254.

Johansen, S., \& Juselius, K. (1990). Maximum likelihood estimation and inference on cointegration-with applications to the demand for money. Oxford Bulletin of Economics and Statistics, 52(2), 169-210.

Kuwornu, J. K. M., Izideen, M. P. M., \& Osei-Asare, Y. B. (2011). Supply response of rice in Ghana: A co-integration analysis. Journal of Economics and Sustainable Development, 2(6), 114.

Kwanashie, M., Gurba, A. G., \& Ajilima, I. (1998). Policy modeling in agriculture: Testing the response of agriculture to adjustment policies in Nigeria. AERC Research Paper 57. African Economic Research Consortium, Nairobi. Pp. 1-54.

Lukonga, I. (1994). Nigeria's non-oil exports: Determinants of supply and demand, 1970 - 1990. International Monetary Fund (IMF) working paper 94/95.

Mesike, C. S., Okoh, R. N., \& Inoni, O. E. (2010). Supply response of rubber farmers in Nigeria. An application of vector error correction model. Medwell Journals of Agriculture, 5(3), 146-150.

Mushtaq, K., \& Dawson, P. J. (2002). Acreage response in Pakistan: A co-integration approach. Agricultural Economics, 27(2), 111-121.
Nerlove, M., \& Bachman, K. L. (1960). The analysis of changes in agricultural supply: problems and approaches. Journal of Farm Economics, 42(3), 531-554.

Oni, S. A. (1969). Production response in Nigerian agriculture: A case study of Palm Produce, 1949-1966. The Nigerian Journal of Economic and Social Studies, 11(1), 81-91.

Osagie, C. (2014). 2015 rice importation ban: Disregard US report, FG urged. Retrieved 17/05/14 from https://allafrica.com/stories/201401140262.html.

Phillips, P. C., \& Ouliaris, S. (1988). Testing for cointegration using principal components methods. Journal of Economic Dynamics and Control, 12(2-3), 205-230.

Rahji, M. Y., \& Adewumi, M. O. (2008). Market supply response and demand for local rice in Nigeria: Implications for selfsufficiency policy. Journal of Central European Agriculture, 9(3), 567-573.

Taiwo, O. (2020). Current state of Nigeria agriculture and agribusiness sector. African Continental Free Trade Area (AfCFTA) workshop. Retrieved from https://www.pwc.com/ng/en/assets/pdf/afcfta-agribusinesscurrent-state-nigeria-agriculture-sector.pdf.

Tanko, M., Iddrisu, A., \& Alidu, A. F. (2016). Determinants of rice yield in Northern region of Ghana, the role of policy. Asian Journal of Agricultural Extension, Economics \& Sociology, 9(2), 1-11.

Wooldridge, J. M. (2003). Introductory econometrics: A modern approach, 2nd edition. South Western College publishing. $\mathrm{p}$. 27.

World Bank (2004). Taxation and state participation in Nigeria's oil and gas sector. Energy Sector Management Assistance Programme (ESMAP) Technical paper; no. ESM 057. Washington, DC. (C) World Bank. Retrived from https://openknowledge.worldbank.org/handle/10986/18078.

Worldometer (2021) www.Worldometers.info. 